\title{
A Therapeutic Answer for the Controversy of Insulin Cardio-protection among Dysglycemic Patients
}

Abdullah M. Nasrat ${ }^{1}{ }^{*}$, Randa M. Nasrat ${ }^{2}$ and Mohammad M. Nasrat ${ }^{3}$

${ }^{1}$ Department of Surgery, Balghsoon Clinic, Jeddah, KSA

${ }^{2}$ Department of Internal Medicine, Helwan General Hospital, Helwan, Egypt

${ }^{3}$ Department of Internal Medicine, Helwan General Hospital, Helwan, Egypt

*Corresponding author: Abdullah M. Nasrat, Department of Surgery, Balghsoon Clinic, Jeddah, KSA, P.O. Box 52611, Jed. 21573, Tel + 966 (012) 667 3645; Fax+ 966 (012) 667 3645; E-mail: abdullahalnasrat@yahoo.com

Rec date: Oct 23, 2015 Acc date: Dec 26, 2015 Pub date: Dec 31, 2015

Copyright: (c) 2015 Nasrat AM, et al. This is an open-access article distributed under the terms of the Creative Commons Attribution License, which permits unrestricted use, distribution, and reproduction in any medium, provided the original author and source are credited.

\begin{abstract}
The study aimed to illustrate the cardio-protective effect of blood-let out cupping therapy in dysglycemia. The controversy of insulin cardio-protection among dysglycemic patients is a confusing challenge. Glucose-insulin disproportion is a major reason for accumulation of acidic metabolites in the body leading to the current controversy about insulin role in cardio-protection. The micro-capillary dysfunction, the improper tissue perfusion with blood and the accumulation of acidic metabolites in the myocardium are leading to each other and could contribute to progression into major cardiac events. Withdrawal of these metabolites could disturb this ischemic vicious circle and offer the answer for the controversy of insulin cardio-protection among dysglycemic patients. Suction in cupping therapy works specifically on the blood trapped within the tissues together with the acidic metabolites which are believed to be functionally obliged to it. Skin scratching with the action of repeated suction delivers nitric oxide to the area which is a potent cardio protectant in health and disease.
\end{abstract}

Seven diabetic patients on insulin with recurrent moderate chest tightness due to variable grades of myocardial ischemia refused coronary catheterization. Therefore; a session of basic cupping therapy on the upper back and front of the chest was advised and employed for them.

Dramatic symptomatic relief and clinical recovery was documented in six patients. They were followed up for 18 months without any further cardiac issues.

On conclusion; cupping therapy in this way becomes a maneuver that could lead to correction of ischemic myocardial situations, and the tissues interstitial space therefore constitutes the intelligent yard where cupping exerts its biological talents.

Keywords: Cardio-protection; Cupping therapy; Dysglycemia; Insulin

\section{Introduction}

The rising challenge of cardiovascular disease constitutes an actual burden. The controversy of insulin cardio-protection among dysglycemic patients is also a challenge. Myocardial ischemia/ reperfusion injury during coronary procedures represents a further challenge [1-4]. The real clue in ischemic cardiac conditions is to prevent progression into critical ischemia than treating it; prophylaxis is always far better than treatment.

The accumulation of toxic metabolites and inflammatory mediators in the tissues and circulation is a fact that has been reported in literature. Glucose/insulin disproportion is a major reason for accumulation of these toxic metabolites in the body. These substances can induce vascular spasm and other effects on vascular endothelium $[4,5]$. Elimination of these toxic elements is a challenge that would definitely help to correct an underlying micro-circulatory error.

\section{$\operatorname{Aim}$}

Demonstration of the cardio-protective effect of blood-let out cupping therapy among dysglycemic patients.

\section{Design and Setting}

Multiple-case clinical study study done in Balghsoon Clinics in Jeddah/Saudi Arabia during Jan. 2011- Oct. 2013.

\section{Patients and Methods}

The study included seven diabetic male patients on insulin with recurrent moderate chest discomfort and pain due to variable grades of myocardial ischemia as documented by electrocardiogram (ECG), cardiac enzymes and echocardiography. Their age ranged between 55 and 63 years, two of them were having a history of coronary stents insertion few months earlier. They were scheduled for coronary catheterization and possible stenting. All patients hesitated towards undergoing a coronary procedure, therefore; a session of basic cupping therapy on the upper back and front of the chest was advised and employed for them. 


\section{Results}

Dramatic symptomatic relief and clinical recovery was documented in six patients based on ECG, cardiac enzymes and echocardiography. They were followed up for 18 months without any further cardiac issues. One patient without previous history of coronary stenting did not experience benefit following the cupping procedure possibly because of being heavy smoker and he was not willing to quit smoking, he followed medical treatment for his heart condition.

\section{Ethical Considerations}

An informed signed consent was taken from all patients, they were made aware about safety of the procedure of cupping therapy and they were free to quit the study whenever they like. The research proposal was approved and the study followed the rules of the Research Ethics Committee of Balghsoon Clinics in Jeddah, Saudi Arabia.

\section{Discussion}

Impairment of the vascular endothelial function caused by excess accumulation of metabolites in the tissues and circulation is involved in the pathogenesis of wide variety of cardiovascular diseases and hence is considered a therapeutic target [1]. Micro-capillary dysfunction, improper tissue perfusion with blood and accumulation of acidic metabolites in the tissues are leading to each other and constitute the main hidden truth behind chronic and major illness [6]. Production of ischemic metabolites within the myocardium due to lack of proper myocardial perfusion constitutes a toxic elementwhich can contribute to progression of the coronary heart disease [7].

Glucose/insulin disproportion constitutes a major metabolic error that could lead to accumulation of acidic metabolites in the tissues and circulation [4]. The continuing controversy about the role of insulin in cardio-protection among patients with dysglycemia should logically indicate the presence of a missed underlying pathology; [4,8] accumulation of acidic metabolites in the body due to glucose/insulin disproportion could be the hidden reason behind this controversy.

Glucose/insulin proportion can never be precisely adjusted except through the function of the human body pancreatic machine pump. Some leaders in diabetes reported that insulin is cardio protective as diabetic patients who receive insufficient doses of insulin develop cardiac events while other pioneers emphasized that insulin is not cardio protective as some patients who are receiving sufficient insulin still developed heart attacks. Patients who receive insufficient insulin will compensate for their energy needs via consumption of lipids leading to production of acidic metabolites. Patients who are receiving sufficient insulin may consume all their glucose, if they are still in need of energy they will gain it from lipid metabolism which would leave also acidic metabolites behind. This would definitely mean that isulindependant diabetic patients would demonstrate accumulation of these toxic metabolites in their tissues and circulation and those patients would no way suffer a cardiac issue during the course of diabetes in their life. A cupping blood-let out therapy on the upper bach and front of chest done once a year or once during the course of diabetes could include major cardioprotection for dysglycemic patients via withdrawal of accumulated metabolites from the body $[9,10]$.

Withdrawal of ischemic tissue metabolites from the body, being interstitial and diffuse, is only feasible via superficial scratching on the skin and suction by the traditional therapeutic cups. Suction in cupping therapy works specifically on the blood trapped within the tissues together with the acidic metabolites which are believed to be functionally obliged to this trapped blood. Skin scratching with the action of repeated suction delivers nitric oxide to the area which is a potent cardioprotectant in health and disease. Sero-clearance mediated through micro-capillary dilatation due to the effect of nitric acid is a further talent of cupping therapy that would improve quality of tissue perfusion with blood and oxygen [10,11]. Cupping blood-let out therapy in this way becomes a maneuver which could lead to correction of an associated ischemic cardiac situation, and the interstitial space is therefore constituting the intelligent yard where cupping exerts its biological talents.

\section{Conclusion}

Cupping therapy can provide good therapeutic cardio-protection for patients with dysglycemia due to glucose/insulin disproportion. Withdrawal of the toxic metabolites from the body could constitute the cupping therapeutic answer for the controversy of insulin cardioprotection among dysglycemic patients, and the interstitial space therefore constitutes the intelligent yard where cupping exerts its biological talents.

\section{Acknowledgements}

The study appreciates the facilities and time allowed by Balghsoon Clinics in Jeddah/Saudi Arabia. The continuous support offered by Abdul-Aziz Al-Sorayai Investment Company (ASIC) in Jeddah/Saudi Arabia, the scientific and emotional support of Dr Ahmed S. Balghsoon are extremely valued and appreciated.

\section{References}

1. Shimokawa H, Yasuda S (2008) Myocardial ischemia: current concepts and future perspectives. J Cardiol 52: 67-78.

2. White HD, Chew DO (2008) Acute myocardial infarction. Lancet 372: 570-584.

3. Darius H, Trampisch HJ, Pittrow D (2008) Comparison of two coronary risk equivalents: diabetes mellitus and peripheral arterial disease. Dtsch Med Wochenschr $133: 2317-2322$.

4. Yu Q, Gao F, Ma XL (2011) Insulin says NO to cardiovascular disease. Cardiovasc Res 89:516-524.

5. Ozben B, Erdogan O (2008) The role of inflammation in acute coronary syndromes. Inflamm Allergy Drug Targets 7:136-144.

6. Morishita K (1972) The Hidden Truth Behind Cancer. San Francisco, George Ohsawa Macrobiotic Foundation.

7. Newton DJ, Khan F, Kennedy G (2008) Improvement in systemic endothelial condition following amputation in patients with critical limb ischemia. Int Angiol 408-412.

8. Kloner RA, Nesto RW (2008) Glucose-insulin-potassium for acute myocardial infarction: continuing controversy over cardioprotection. Circulation 117: 2523-2533.

9. Nasrat AM (2015) The dramatic spread of diabetes mellitus worldwide and influence of Helicobacter pylori. The 4th Complementary Medicine Conference on Homeopathy, Lotus Holistic Center, Abu dhabi, Emirates.

10. Nasrat AM (2012) Role of blood-let out cupping therapy in angina and angina risk management, emergency Vs elective. The 22nd International scientific session of Saudi Heart Association, Riyadh.

11. Nasrat AM (2010) Role of blood-let out cupping therapy in taming the wild hepatitis B Virus. The International Congress of Aesthetic Dermatology and Preventive medicine, Paris. 